\title{
HYDROLOGICAL EFFICIENCY EVALUATION TOOL OF URBAN STORMWATER BEST MANAGEMENT PRACTICES
}

\author{
A. ROMNÉE \& A. DE HERDE \\ Architecture et Climat, Université catholique de Louvain, Belgium.
}

\begin{abstract}
The Brussels Environment Agency designed a decision-support tool ( $Q U A D E A U)$ for the sustainable management of stormwater in urban and developed areas. The tool aims to evaluate and compare alternative scenarios for reducing water runoff in public spaces inside any neighbourhood. QUADEAU is an easy to use tool for urban designers and watershed practitioners allowing the evaluation of the hydrological efficiency of any public space in a renovation or a new urban project designed with best management practices (BMP). It is a tool thought out to provide processes of optimization and selection of BMP to meet the hydrological objectives and the program needs of the public space project. This paper describes how QUADEAU is setup and how BMP are evaluated inside the tool. Any public space project is modelled in the tool by giving specific characteristics of all areas of the project. Connections between surfaces of the project are introduced within the tool by creating flow networks. BMPs are selected according to site constraints and program requirements of the urban project before being designed by giving values to specific parameters for each BMP selected. The hydrological efficiency of the project, i.e. the amount of water that does not reach the outlet because it has been managed earlier in BMP, is evaluated during and after the design rain event. The tool gives the user the opportunity to optimize his project if the hydrological efficiency does not match the hydrological thresholds determined in function of the imperviousness of the neighbourhood, the type of project and the local hydrology.
\end{abstract}

Keywords: Best management practices, design-support tool, modelling and simulation tool, sustainable stormwater management.

\section{INTRODUCTION}

In the Brussels Capital Region, in the last 50 years, the soil waterproofing rate has doubled due to urbanization, from $18 \%$ in the year 1955 to $37 \%$ in the year 2006 [1]. Urbanization engaged all over the world in the twentieth century; extensive environmental impacts, such as reduction of biodiversity, urban island effect; and soil deterioration were led by soil sealing. Urbanization reduces the amount of undeveloped and natural lands and thus reduces the ability of urban areas to mitigate floods. Urbanization is responsible for tremendous disruption of the natural water cycle: the runoff is increased while the infiltration and the evaporation are decreased. Urban development combined with a changing climate may also cause alterations in the hydrologic regime resulting in more frequent extreme events, increasing peakflows, lowering baseflows, and increasing stream erosion [2]. Major traditional public works, such as combined sewer and stormwater reservoirs, have proved their limits to mitigate these increasing risks.

Since two decades, a new paradigm in urban water management has emerged, fostering a sustainable approach in stormwater management. This approach is highlighted by the incorporation of on-site low impact development techniques (LID) and best management practices (BMP). LID is intended to restore the natural condition or to attenuate the impact of urban development and to maximize on-site stormwater control. As parts of LID, BMPs are small scale decentralized 'green techniques' used to prevent, control, and treat stormwater. Many design guidelines for BMPs are available [3,4]. A large array of BMP is available, such as rain gardens, swales, green roofs, trenches, infiltration basins, infiltration pits, porous pavements, etc., but their selection and 
evaluation require modelling tools in order to consider their contribution to the improvement of urban water cycles.

In 2007, Elliott and Trowsdale [5] inventory 10 models for urban stormwater. All of them were produced in North America or Australia. Each model does not propose a full array of BMP but only a few of them are cited above. All hydraulic aspects of infiltration, storage, evaporation, and runoff are not evaluated by each model. The models are not specific to BMP evaluation. None of them give a global evaluation of the hydrological efficiency of BMP. Several models are already available to assess the effectiveness of BMPs in the urban environment. These models allow designers to evaluate and compare different sustainable stormwater management scenarios in order to meet mandatory or voluntary performance standards. These models are designed to predict environmental outcomes as water quality, water flow quantity, streamflow, groundwater recharge, etc.

Models are designed to be effective in a specific territory scale: a single site, a neighbourhood, a watershed, a city. They also need lot of data on these specific sites. Other simple models exist and require relatively limited input data and no strong technical expertise. Among these models, the EPA National Stormwater Calculator [6] estimates the volume and frequency of runoff from a selected site based on local soil, topography, climate data, land cover and BMP data. The Werf BMP Select Model [7] is intended for project ranging from the site scale up to the watershed scale. This model requires inputs data as hourly precipitation, land use distribution, and BMP parameters in order to estimate the runoff volume, the pollutant loads, and the costs.

Recognizing that there were no intuitive and easy to use without engineering knowledge modelling tools available to systematically evaluate and compare BMP solutions, the Brussels Environment Agency decided to develop a decision-support tool for the evaluation of the impact on the urban water cycle of any public space project designed with BMP [8]. QUADEAU is encoded within an Excel spreadsheet, which means that it is intuitive and easy to use for most individuals without specific engineering knowledge. The tool ( $Q U A D E A U)$ aims to evaluate and compare alternative scenarios for reducing water runoff in public spaces inside any neighbourhood. To address the needs of urban designer and the requirements of local government, QUADEAU was developed to focus on two major goals. The first objective of the tool is to assess the hydrological efficiency of a public space project designed with BMP by giving the amount of stormwater managed by the BMP that does not reach the outlet. Secondly, by the assessment and design of BMP, QUADEAU promotes the integration of BMPs in the public space. This alternative stormwater management to pipes system fosters the creation of a surface rain water sewer system. To reach these two objectives, the model takes into account simple inputs data on the local hydrogeology, the characteristics of the urban surfaces, and the type of BMP. A project is modelled in the tool by creating flow networks between different areas of the project. It estimates the amount and flow of stormwater that percolates throughout the soil, evapo(transpi)rates, accumulates into BMP and finally flows into the downstream reaching mandatory or voluntary hydraulic objectives.

This paper summarizes the development of the modelling, evaluation, and optimization processes already developed by Romnée et al. [9]. The paper focuses, on one part, on the processes of selection and design of BMP actives in $Q U A D E A U$, and on other part, on the hydrological efficiency evaluation process that operates in the tool. Demonstrating that $Q U A D E A U$ is a powerful and easy-to-use tool, some print screen figures of a case study illustrate the paper.

\section{MODELLING, EVALUATION, AND OPTIMIZATION PROCESSES}

QUADEAU is composed of seven modules [9], allowing the modelling of the public space project and the evaluation of its hydrological efficiency. The tool focuses on limiting the extent and the 
complexity of inputs data relative to the site and the neighbourhood. The designer models the stormwater management designed scenario and receives a synthesis of the hydrological efficiency of his project. If the output data does not match the hydrological threshold objectives, the designer is invited to optimize his designed scenario by changing BMP parameters.

\subsection{Inputs data}

Three main characteristics concerning the impervious soil rate, the nature of the project, and the potential of infiltration have to be mentioned as site and neighbourhood inputs data. These characteristics influence the hydrological objectives that the project has to reach: a project located in densely urbanized areas will be more difficult to be expected because of the existing infrastructures and buildings in the neighbourhood; objectives will be more severe for new construction projects than for renovation ones, and objectives will be adapted to the soil infiltration rate.

A soil regional database, directly available from the tool, is used to obtain the imperviousness rate of the surrounding areas of the project. The tool is designed to be effective for both new or renovation public space project. A map produced by De Bondt and Claeys [10] and directly available from the tool is used to identify the potential infiltration areas within the Brussels region according to the soil permeability, the local hydrogeology, the slope, and the protection zone of groundwater pumping.

A hydraulic network is composed of several nodes. Two types of nodes have to be defined for each project modelled within $Q U A D E A U$ : the relations between the site and the neighbourhood and the many surfaces of the project. To relate and connect the public space project with the neighbourhood, user specifies the site relationships with upstream public spaces and with roofs of surrounding buildings. The tool allows designer to relate the site to many upstream public spaces and roofs of surrounding buildings by introducing the chronicle water flow of these surrounding elements as inputs data. A chronicle water flow is the amount of water generated by the site for each time increments of 5 min during the rainfall. Where the precise chronicles water flows are unknown, the tool estimates the amount of water coming from these upstream public spaces and these roofs based on their area and their covering materials. In addition to these two kinds of connections of the site to the neighbourhood, a site project is modelled in the tool by introducing two types of surfaces: the tributary surfaces and the collecting surfaces. Tributary surfaces may be public spaces (e.g. street, sidewalk...), rear areas (e.g. driveway parking, small gardens...), flat roofs (e.g. extensive or intensive green roof), or sloped roofs. Tributary surfaces generate water flow during the rain without collecting it (except for green roof). Each tributary surface is identified by its dimensions, its covering materials, and its vegetation cover. Collecting surfaces collects into BMP water from surrounding surfaces during the rain and evacuate the stocked water by infiltration, evaporation, and with controlled outflow to the outlet after the rain. One BMP technique is assigned to each collecting surface that is identified in the tool by its dimensions and its BMP choice.

\subsection{Design scenario}

A design scenario is modelled and composed of three elements: the hydrological objectives that the project has to reach, the networks flows between the nodes, and the BMP technique for each collecting surface. At any time in the modelling process or if the design does not match the hydrological objectives at the end of the evaluation process, the user may adjust or is advised to modify one of these elements in order to optimize its design scenario. 
The hydrological objectives that the project has to reach are of two types: the return period of the design storm and the maximum leakage flow of the site to the outlet. These two objectives are determined in function of the total imperviousness of the neighbourhood, the type of the project (new or renovation), and the local hydrology. Objectives are more severe: if the imperviousness is low (it should be easier to set up BMP if the neighbourhood is poorly built), if the project is a new public space, and if the local hydrogeology allows infiltration (or pervious soil, in addition to the slowdown of exceptional rainfall, it is recommended to infiltrate water for current rain (return period $\leq 10$ years)). QUADEAU offers the opportunity to choose mandatory or voluntary couple of objectives corresponding to the reality of the project.

Hydraulic networks are composed of nodes and relations between these nodes that transport rain water up to the outlet. Four different networks by project can be elaborate in $Q U A D E A U$. Networks are identified in the tool by the selection of a unique outlet. The nodes are introduced in the inputs data section and represent the tributary and collecting surfaces, the upstream public spaces and the surrounding building roofs. By modelling convention, the relations between the nodes are of three types: water generated by upstream public spaces or by surrounding building roofs may flow to a tributary or to a collecting surface; water generated by a tributary surface may flow to another tributary surface or to a collecting surface and water generated and collected by a collecting surface may flow to another collecting surface or reach the outlet.

One BMP technique has to be selected for each collecting surface of the project. The choice of a technique among the others behoves to the designer but the tool may orientate the choice. The tool operates and proposes a first BMP selection for each collecting surface based on specific elements correlated to four local criteria (see Section 3). For each BMP, the tool offers the designer the possibility to adjust some specific parameters in order to correctly model and optimize the project (see Section 3).

\subsection{Outputs}

As explained in more detail in Section 4 of this paper, the water balance is calculated for each time increments of 5 min during the rainfall and for each surface. For all tributary surfaces, $Q U A D E A U$ calculates the amount of water precipitated on the site, the amount of injected water (the part of rainwater that flows from a surface to another, according to the defined network), the amount of water intercepted by the vegetation, the amount of infiltrated water, the amount of retention stored water, and the amount of runoff water. For all collecting surfaces, the amount of water accumulated in the BMP technique is also calculated.

At the end of the evaluation process, the tool gives the water balance and the hydrological efficiency for all networks during and after the rainfall. The synthesis gives the total volume of water that is intercepted by the vegetation, percolates through the soil, accumulates in the best management practice techniques, and finally flows into the outlet during the rain. The synthesis gives also the total volume of water that evaporates, percolates through the soil, and flows into the outlet and the time for draining of structure after the rain.

Finally, the tool concludes on the achievement of the hydrological objectives. To achieve the objectives, two criteria are taken into account:

1. Is the amount of water stored into BMPs integrated into the network lower or equal to the maximum storage capacity of the network?

2. Is the amount of water discharged to the outlet is lower or equal to the maximum authorized dischargeable volume (based on the maximum leakage flow to the outlet)? 
According to the evaluation of these two criteria (i.e. if the answer to one of both question is negative), the tool eventually advises the user to optimize his design scenario (see Sections 3.2 and 4.3).

\section{SELECTION AND DESIGN OF BMP}

QUADEAU promotes and focuses on the integration of BMP into public spaces in order to (partially) restore the pre-development water balance. Moreover, QUADEAU advices urban designers in the selection of BMP to integrate in their specific project by considering the local soil characteristics, the localization of the BMP into the project, the main hydrological principle required, and the environmental opportunities of the project.

\subsection{Selection process of BMP}

As explained in Section 2.2, the choice of a BMP for each collecting surface of the project behoves to the user of the tool. $Q U A D E A U$ orientates and advises the user for the selection of the most adapted BMP to its project. The stormwater BMPs that can be simulated in the model include swale, permeable pavement, stormwater trees, infiltration basin, dry basin, water basin, bioretention, rain garden, drainage trench, and infiltration pit.

The selection of a BMP is complex and asks to consider a large amount of parameters correlated to the site, to the project, and to the BMP themselves. The selection process aims to determine the most adapted BMP taking these parameters into consideration. QUADEAU operates this selection for each collecting surface based on four criteria: the site constraints, the location of the collecting surface in the network, the hydrological principle required, and the environmental amenities of the project. For each collecting surface of the project, the designer has to mention these criteria and the tool selects some BMP adapted to these data.

\subsubsection{Location of the BMP}

The location of a collecting surface into the drainage network of the project impacts the selection of a BMP appropriated to the surface (Table 1).

Table 1: Possible location of BMPs in the network.

\begin{tabular}{lcccc}
\hline & Pre-treatment & Source & Transport & Outlet \\
\hline Dry basin & $+/-$ & $+/-$ & & + \\
Water basin & $+/-$ & $+/-$ & & + \\
Infiltration basin & $+/-$ & $+/-$ & & + \\
Bioretention & + & $+/-$ & $+/-$ & \\
Drainage trench & & $+/-$ & + & + \\
Infiltration pit & & + & & \\
Rain garden & $+/-$ & + & + & \\
Swale & $+/-$ & $+/-$ & $+/-$ & \\
Permeable pavement & & + & & \\
Stormwater trees & $+/-$ & + &
\end{tabular}

+: Suited to this location in the network; +/-: may be suitable for this location in the network; (empty): is not suitable for this location in the network. 
According to Rivard [11], CIRIA [3], and Azzout [12], four specific locations of BMP may be encountered:

- The 'pre-treatment location' is a location for BMP capable of removing deposits and debris upstream of the other BMP.

- The 'source location' is the most upstream location of the network for BMP capable of infiltration and storage in order to reduce the water flow.

- The 'transport location' is a location for BMP slowing down and reducing stormwater runoff.

- The location at 'the end of the network' is specific for BMP considered as network's outlet.

3.1.2 Main and secondary hydrological processes

A BMP may be selected according to the hydrological process corresponding to the specific location of a collecting surface in the project.

Four hydrological processes can be used to manage and control stormwater inside the BMP: runoff, infiltration, storage, and evaporation. Due to specific geometrical and covering material characteristics, one of these four hydrological processes is more relevant to each BMP, this is what we call the main hydrological process, in accordance with CIRIA [3]. BMPs can be categorized broadly by whether their main hydrological process is considered to be the infiltration (e.g. infiltration basin), the storage (e.g. water basin), to slow runoff down (e.g. permeable pavement), or the evaporation (e.g. stormwater trees). For instance, the main hydrological process of a water basin is to store water during the rainfall.

BMP techniques are relatively complex structures that manage stormwater by different ways, especially when they contribute to a stormwater management train, as expected for an efficient drainage system. Besides the main hydrological process, each BMP may also potentially present some opportunities for other stormwater management processes, subject to design, that we call secondary hydrological processes. For instance, once a water basin has stored water (storage is the main hydrological process), this BMP may evaporate and infiltrate the stored water (secondary process). Table 2 summarizes the main and the secondary hydrological processes of the BMPs.

\subsubsection{Site constraints}

A public space project site may constrain the selection of BMPs. Indeed, bad soil conditions, such as poor absorbency or poor soil bearing, or groundwater conditions, such as vulnerable groundwater or shallow water table, or spatial conditions, such as steep site or little land space, may influence and constraint the selection of an appropriate BMP.

Many particular site constraints may be identified and be specific to each site. QUADEAU deals with nine general site constraints that influence the possible implementation of a BMP. BMPs are more or less compatible with these site constraints and it is always better to select a BMP compatible with the maximum number of site constraints. Table 3 summarizes the site constraints considered in the tool and the compatibility with BMPs.

\subsubsection{Environmental amenities}

In addition to their stormwater management ability, BMPs offer lot of other environmental amenities. Five environmental amenities are considered into the tool: the supply of groundwater, the supply of vegetation, the contribution to a blue frame or to a green frame. Another amenity is also pointed out: it is the multifunctional character of a technique that can manage stormwater on one hand and be used for another activity (e.g. sport area) on the other hand. 
Table 2: Main and secondary hydrological processes of BMPs.

\begin{tabular}{lcccc}
\hline & Runoff & Infiltration & Storage & Evaporation \\
\hline Dry basin & & & + & $+/-$ \\
Water basin & & $+/-$ & + & $+/-$ \\
Infiltration basin & + & + & + & \\
Bioretention & $+/-$ & + & $+/-$ & \\
Drainage trench & & + & $+/-$ & $+/-$ \\
Infiltration pit & + & $+/-$ & & $+/-$ \\
Rain garden & + & $+/-$ & & + \\
Swale & $+/-$ & $+/-$ & + \\
Permeable pavement & & + & \\
Stormwater trees & & & & \\
\hline
\end{tabular}

+: Main hydrological process; +/-: secondary hydrological process; (empty): the process is not relevant.

Table 3: BMPs compatible with site constraints.

\begin{tabular}{|c|c|c|c|c|c|c|c|c|c|}
\hline & 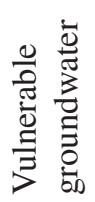 & 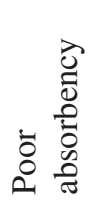 & 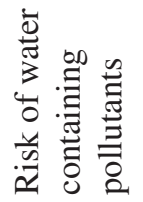 & 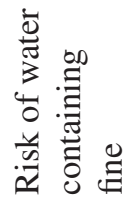 & 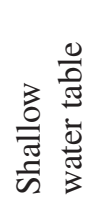 & 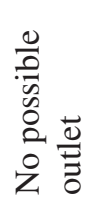 & 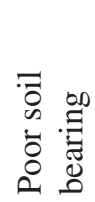 & $\begin{array}{l}\cdot \stackrel{0}{\infty} \\
\frac{0}{0} \\
\frac{\Delta}{\infty}\end{array}$ & 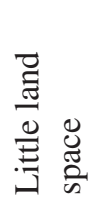 \\
\hline Dry basin & + & + & + & + & & & + & + & \\
\hline Water basin & & + & & & + & & + & + & \\
\hline Infiltration basin & & & & & & + & + & + & \\
\hline Bioretention & & & & + & & + & + & & + \\
\hline Drainage trench & & & & & & + & + & + & + \\
\hline Infiltration pit & & & & + & & + & + & + & + \\
\hline Rain garden & & & & & & + & + & & \\
\hline Swale & + & + & & + & + & + & + & + & \\
\hline Permeable pavement & & + & & & & & & & \\
\hline Stormwater trees & & & & & + & & + & + & + \\
\hline
\end{tabular}

+ : This BMP is compatible with this site constraint; (empty): this BMP is not compatible with this site constraint.

Environmental amenities of a site must be recognized by the urban designer. BMPs support more or less these environmental amenities and it is better to select a BMP supporting the environmental amenity recognized by the designer. Table 4 summarizes the environmental amenities supported by BMPs.

\subsection{Design parameters of BMP}

All parameters (geometry, materials, tree cover, type) of each BMP can be introduce and adjust in $Q U A D E A U$ in order to correctly model the project. Table 5 summarizes the design parameters for each BMP that can be optimized in the tool. 
Table 4: Environmental amenities of BMPs.

\begin{tabular}{|c|c|c|c|c|c|}
\hline & $\begin{array}{l}\text { Supply of } \\
\text { groundwater }\end{array}$ & $\begin{array}{l}\text { Supply of } \\
\text { vegetation }\end{array}$ & Blue frame & Green frame & $\begin{array}{c}\text { Multi- } \\
\text { functional }\end{array}$ \\
\hline Dry basin & & & & $+1-$ & + \\
\hline Water basin & $+/-$ & $+/-$ & + & $+/-$ & $+1-$ \\
\hline Infiltration basin & + & + & & $+/-$ & + \\
\hline Bioretention & $+/-$ & + & & $+/-$ & $+/-$ \\
\hline Drainage trench & + & $+/-$ & & & \\
\hline Infiltration pit & + & $+/-$ & & & \\
\hline Rain garden & $+1-$ & + & & $+1-$ & + \\
\hline Swale & $+1-$ & $+/-$ & $+1-$ & + & \\
\hline Permeable pavement & $+/-$ & & & & $+/-$ \\
\hline Stormwater trees & $+/-$ & + & & + & $+/-$ \\
\hline
\end{tabular}

+: Highly supported; +/-: supported; (empty): not supported.

Table 5: Design parameters specific to each BMP.

\begin{tabular}{|c|c|c|c|c|c|c|c|c|c|c|c|c|}
\hline & 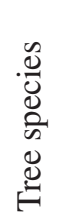 & 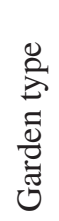 & 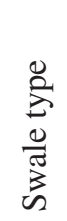 & $\frac{\stackrel{8}{2}}{\stackrel{0}{0}}$ & 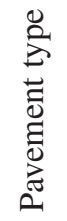 & 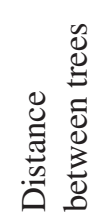 & 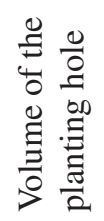 & $\begin{array}{l}\frac{5}{0} \\
\frac{0}{3} \\
0 \\
0 \\
0 \\
0 \\
0\end{array}$ & 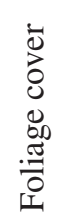 & 言 & 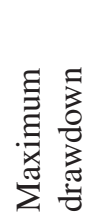 & 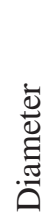 \\
\hline Dry basin & & & & & + & & & + & & + & & \\
\hline Water basin & & & & & + & & & + & & + & + & \\
\hline Infiltration basin & & & & & + & & & + & & + & & \\
\hline Bioretention & & & & & + & & & & + & & & \\
\hline Drainage trench & & & & & + & & & & & + & & \\
\hline Infiltration pit & & & & + & + & & & & & + & & + \\
\hline Rain garden & & + & & & + & & & & + & + & & \\
\hline Swale & & & + & & + & & & + & + & + & + & \\
\hline Permeable pavement & & & & & + & & & & + & & & \\
\hline Stormwater trees & + & & & & + & + & & & & & & \\
\hline
\end{tabular}

The length and width of the techniques do not appear in Table 5 because these dimensions depend on the size of the collecting surface hosting the BMP.

The urban designer may adjust all parameters for each BMP of its project in order to meet the hydrological objectives of its project (see Section 4.3).

\section{HYDROLOGICAL EFFICIENCY CALCULATION}

The hydrological efficiency is a metric that compares the water balance of a site project including BMPs to a site project designed with a conventional drainage system. This metric gives the amount of water that does not reach the outlet because it has been managed (stored, infiltrated, evaporated) 
by BMPs compared with the total precipitation. Assuming that with conventional drainage system the total precipitation reaches the outlet, the hydrological efficiency measures the relevance of the integration of BMPs into public space in order to restore pre-development water balance.

By definition of the hydrological efficiency, its determination requires the calculation of the water balance for each surface of the project. The water balance is given by the determination of runoff losses: the interception and evaporation, the surface retention, the infiltration, and the storage [11].

\subsection{Definition of runoff losses}

The entire amount of water precipitated on a surface does not generate runoff. Many runoff losses have to be taken into account in order to determine the part of the water precipitation that generates runoff. Rivard [11] defines four types of direct runoff losses:

- The interception is the part of the precipitation intercepted by the vegetation. This interception will then be evaporated. The interception is the part of the precipitation that never reaches the ground. The interception depends on the size of the canopy of the vegetation.

- The infiltration is the amount of water that percolates into the soil and feeds groundwater or subsurface flows. The amount of infiltrated water depends on the local hydrogeology, the type of soil, and the conditions of soil moisture.

- The surface retention is the amount of water stored in depression surfaces that does not contribute to runoff or infiltration. The capacity of surface retention depends on the covering material and the slope of the site. The stored water will finally be evaporated.

- The storage is the amount of water that is temporarily stored in a structure before being discharged by evaporation, and/or by infiltration and/or by controlled leakage flow rate.

Net rain then represents the amount of runoff on a surface where all runoff losses are evaluated.

Rivard [11] and Musy [13] evoke that in urban hydrology, the runoff process considers the concept of Horton and its definition of infiltration: surface runoff is generated after deduction of initial runoff losses and when the rainfall intensity exceeds soil infiltration capacity.

QUADEAU calculates the water balance and the net rain for each surface of the project.

\subsection{Calculation of runoff losses}

The water balance, and thus the net rain and the runoff losses, is calculated in the tool for each surface of the project and for each time increments of $5 \mathrm{~min}$ all along the $4 \mathrm{~h}$ of the design storm. In $Q U A D E A U$, the design storm used lasts $4 \mathrm{~h}$ and is constructed from the middle by successive time increments of $5 \mathrm{~min}$ and its peak intensity occurs after $120 \mathrm{~min}$. The resulting curves are symmetrical and their peak intensity depends on the return period.

\subsubsection{Net rain}

By definition, the net rain is the difference between the total precipitation and the runoff losses. We call the water flow chronicle, the net rain $\mathrm{N}(\mathrm{t})$ of a surface for each time increments of 5 min during the design storm.

Moreover, inserted into a network, a surface may receive water coming from surrounding surfaces. We call this amount of water the 'injected flow'. By hypothesis, we assume that the transfer of water between surfaces is instantaneous because the tool focuses on the global water balance. 
Collecting surfaces differ from tributary surfaces by their storage capacity. Thus, the storage runoff loss is only calculated for collecting surfaces. QUADEAU calculates the net rain $\mathrm{N}(\mathrm{t})$ for each time increments of 5 min $t$ as follows, according to the specific type of surface:

$$
\begin{gathered}
N(t)=[P(t)+\operatorname{Inj}(t)]-[i(t)+R(t)+I(t)] \\
N(t)=[P(t)+\operatorname{Inj}(t)]-[i(t)+R(t)+I(t)+S(t)]
\end{gathered}
$$

Equation (1) is for tributary surfaces and eqn (2) is for collecting surfaces. In eqns (1) and (2), the different terms stand for:

$\mathrm{P}(\mathrm{t}) \quad$ The intensity of precipitation during the time increments of $5 \mathrm{~min}$ corresponding to the return period of the design storm.

Inj(t) The injected flow during the time increments of 5 min from surrounding nodes connected to the surface in the network.

$\mathrm{i}(\mathrm{t}) \quad$ The precipitation intercepted by the vegetation during the time increments of $5 \mathrm{~min}$.

$\mathrm{R}(\mathrm{t}) \quad$ The surface retention of the surface during the time increments of $5 \mathrm{~min}$

$\mathrm{I}(\mathrm{t}) \quad$ The amount of water infiltrated into the soil during the time increments of $5 \mathrm{~min}$

$\mathrm{S}(\mathrm{t}) \quad$ The amount of water stored in BMP during the time increments of $5 \mathrm{~min}$.

The injected flow coming from a tributary surface or a collecting surface of the project is directly introduced as Inj(t) in eqns (1) and (2). But the injected flow may also come from upstream public spaces or surrounding building roofs connected to a surface. QUADEAU offers the opportunity to introduce the accurate water flow chronicle of these elements if it has been previously evaluated by the tool. Otherwise, $Q U A D E A U$ estimates the water flow chronicle (i.e. the net rain to be injected) $\mathrm{N}(\mathrm{t})$ of these elements as follows:

$$
\mathrm{N}(\mathrm{t})=\mathrm{P}(\mathrm{t}) * \mathrm{t} * \mathrm{~A} * \mathrm{C}_{\mathrm{r}}
$$

The terms of eqn (3) are different according to whether it is an upstream public space or a surrounding roof:

A The area of the upstream public space or the area of the surrounding roof

$\mathrm{C}_{\mathrm{r}} \quad$ The runoff coefficient of the covering material of the upstream public space or the runoff coefficient of the roofing material of the surrounding building

$\mathrm{T} \quad$ The time increment of $5 \mathrm{~min}$

QUADEAU automatically selects in a database the runoff coefficient corresponding to the covering material of the surface introduced by the user.

\subsubsection{Interception}

QUADEAU calculates the interception of rainwater by the vegetation $\mathrm{i}(\mathrm{t})$ for each time increments of 5 min $\mathrm{t}$ as follows:

$$
\mathrm{i}(\mathrm{t})=\frac{\mathrm{A}}{1000} * \frac{\mathrm{C}_{\mathrm{e}}}{24} * \mathrm{t} * \mathrm{c}
$$

Terms of eqn (4) stand for:

A The area of the surface (tributary or collecting) in $\mathrm{m}^{2}$

C The vegetation cover of the surface in $\%$

$\mathrm{C}_{\mathrm{e}} \quad$ The evaporation coefficient of the vegetation in $1 / \mathrm{m}^{2} . \mathrm{d}$

$\mathrm{T} \quad$ The time increment of $5 \mathrm{~min}$ in $\mathrm{h}$ 
By hypothesis, $\mathrm{C}_{\mathrm{e}}$ is considered as a constant and equal to $4 \mathrm{l} / \mathrm{m}^{2}$.d. By hypothesis, evapotranspiration is calculated considering summer conditions with a maximum evaporation coefficient and foliage cover.

\subsubsection{Infiltration}

The infiltration capacity of the soil is considered to be constant throughout the design storm and equal to the absorption capacity at saturation $\mathrm{K}_{\mathrm{S}}$ measured on site. While the intensity of the precipitation $\mathrm{P}(\mathrm{t})$ is lower than the absorption capacity at saturation $\mathrm{K}_{\mathrm{S}}$, the infiltration equals the precipitation. As soon as the intensity of the precipitation $\mathrm{P}(\mathrm{t})$ is higher than the absorption capacity at saturation, the infiltration $\mathrm{I}(\mathrm{t})$ is calculated as follows:

$$
\mathrm{I}(\mathrm{t})=\left(1-\mathrm{C}_{\mathrm{r}}\right) * \mathrm{~K}_{\mathrm{S}} * \mathrm{U} * \mathrm{~A} * \mathrm{t}
$$

Terms of eqn (5) represent:

$\mathrm{C}_{\mathrm{r}} \quad$ The runoff coefficient of the covering material of the surface

A The area of the surface (tributary or collecting) in $\mathrm{m}^{2}$

$\mathrm{K}_{\mathrm{S}} \quad$ The absorption capacity of the soil at saturation in $\mathrm{m} / \mathrm{h}$

$\mathrm{U} \quad$ The clogging coefficient of the permeable soil

$\mathrm{T} \quad$ The time increment of $5 \mathrm{~min}$ in $\mathrm{h}$

QUADEAU asks the user to realize a percolation test on the site [4] in order to measure the absorption capacity of the soil at saturation $\mathrm{K}_{\mathrm{S}}$. This measurement is introduced in the tool by the user as an input data.

To take into account the effect of the compaction and clogging on the decrease of the infiltration capacity of a soil, a safety factor $\mathrm{U}$ is applied to the value of the absorption capacity at saturation. Leeflang [14] proposes to take 0.5 as value for $U$ if $K_{\mathrm{S}}$ is measured on site.

\subsubsection{Surface retention}

The maximum volume of surface retention $\mathrm{R}_{\max }$ is calculated by multiplying the surface area $\mathrm{A}$ by the maximum retention height $\mathrm{h}$ corresponding to the covering material of the surface. The maximum retention height depends on the nature of the covering material. To calculate $\mathrm{R}_{\max }, Q U A D E A U$ selects in a database the retention height corresponding to the covering material of the surface introduced by the user.

The surface retention $R(t)$ at time $t$ is the part of the precipitation $P(t)$ at time $t$ less the interception $i(t)$ and the infiltration $I(t)$ at time $t$ accumulated on the surface until it reaches $R_{\text {max }} \cdot R(t)$ is evaluated as follows:

$$
\text { while } \mathrm{R}_{\mathrm{t}-1}<\mathrm{R}_{\max }, \mathrm{R}(\mathrm{t})=[\mathrm{P}(\mathrm{t})+\operatorname{Inj}(\mathrm{t})]-[\mathrm{i}(\mathrm{t})+\mathrm{I}(\mathrm{t})] \text { and } \mathrm{R}_{\mathrm{t}}=\mathrm{R}_{\mathrm{t}-1}+\mathrm{R}(\mathrm{t})
$$

Equation (6) means that the water accumulates on the surface until $R_{\max }$ is reached. $R(t)$ in eqn (6) is thus the increment of surface retention at time $t$.

\subsubsection{Storage}

As a reminder, in the tool, the storage opportunity differentiates a collecting surface and a tributary surface. The water is stored inside the BMP technique incorporated in the collecting surface. The maximum storage capacity $\mathrm{S}_{\max }$ depends on the geometrical characteristics and the design of the BMP. In $Q U A D E A U$, filling a storage structure is progressive depending on the hydrograph of the design storm. Although the maximum storage capacity of the BMP structure is not reached, the water that is not intercepted or infiltrated or superficially retained or flowed at controlled rate will be stored. Once reached the maximum storage capacity, the water overflow generates runoff. 
The storage $\mathrm{S}(\mathrm{t})$ is iteratively calculated as follows:

$$
\text { while } \mathrm{S}_{\mathrm{t}-1}<\mathrm{S}_{\max }, \mathrm{S}(\mathrm{t})=[\mathrm{P}(\mathrm{t})+\operatorname{Inj}(\mathrm{t})]-[\mathrm{i}(\mathrm{t})+\mathrm{I}(\mathrm{t})+\mathrm{R}(\mathrm{t})] \text { and } \mathrm{S}_{\mathrm{t}}=\mathrm{S}_{\mathrm{t}-1}+\mathrm{S}(\mathrm{t})
$$

Equation (7) means that the water accumulates in the BMP storage structure until $S_{\max }$ is reached. $S(t)$ in eqn (7) represents the increment of storage at time t.

\subsection{Hydrological efficiency}

Once all runoff losses and net rain have been calculated for each surface and for each network of the project, $Q U A D E A U$ concludes by giving the hydrological efficiency of the project.

The global hydrological efficiency of the project is compared with the hydrological objectives (see Section 2.2) and QUADEAU:

- advises the user in an optimization of his design scenario if the hydrological objectives are not met. Optimization tips focus on increasing the storage volume by changing the geometry of a $\mathrm{BMP}$, reducing the leakage flow of the site at the outlet, or slowing down the rain flow by modifying or by increasing the number of BMPs.

- informs the user of the sewage duration of BMP if the hydrological objectives are met.

\section{ILLUSTRATIVE CASE STUDY}

Illustrating the modelling, evaluation, and optimization processes, an illustrative case study, in a typical Brussels street, based on imagined data, was undertaken to demonstrate how to apply the tool. The project aims to introduce some BMPs into the new profile of the street. This case study highlights the core functions of $Q U A D E A U$ and its applicability following the seven-module structure of the tool [9].

\subsection{Study site}

The site is a common residential single-way street located south-west of Brussels. The street is bordered with residential surrounding buildings (SB) with small front gardens ( $3 \mathrm{~m}$ wide). The street is related to an upstream public space (UPS1) that flows into the projected street. Before renovation, the street profile was composed by two sidewalks with trees ( $2.7 \mathrm{~m}$ wide), a single road ( $3.9 \mathrm{~m}$ wide), and a parking area on the right $(2 \mathrm{~m}$ wide). Figure 1 is the design of the project for the new profile of the case study street.

The project introduces a swale $(\mathrm{C} 1)$ between the road and the sidewalk on the right, to renovate the covering material of the parking area to favour infiltration $(\mathrm{C} 2)$ and to orientate the water running off the sidewalk on the right into stormwater trees (C3).

In addition to the identification of the different parts and surfaces of the project, the user has to define the network(s) of run off. The illustrative case study presents two networks identified by both outlet 1 and 2. Figure 2 illustrates the conceptual networks of the project.

\subsection{Inputs data}

\subsubsection{Site and neighbourhood module}

The project aims to redefine a new profile to the street; so this is a renovation project. Site-specific hydrology parameters were derived from the potential infiltration areas map [10] and the saturated 


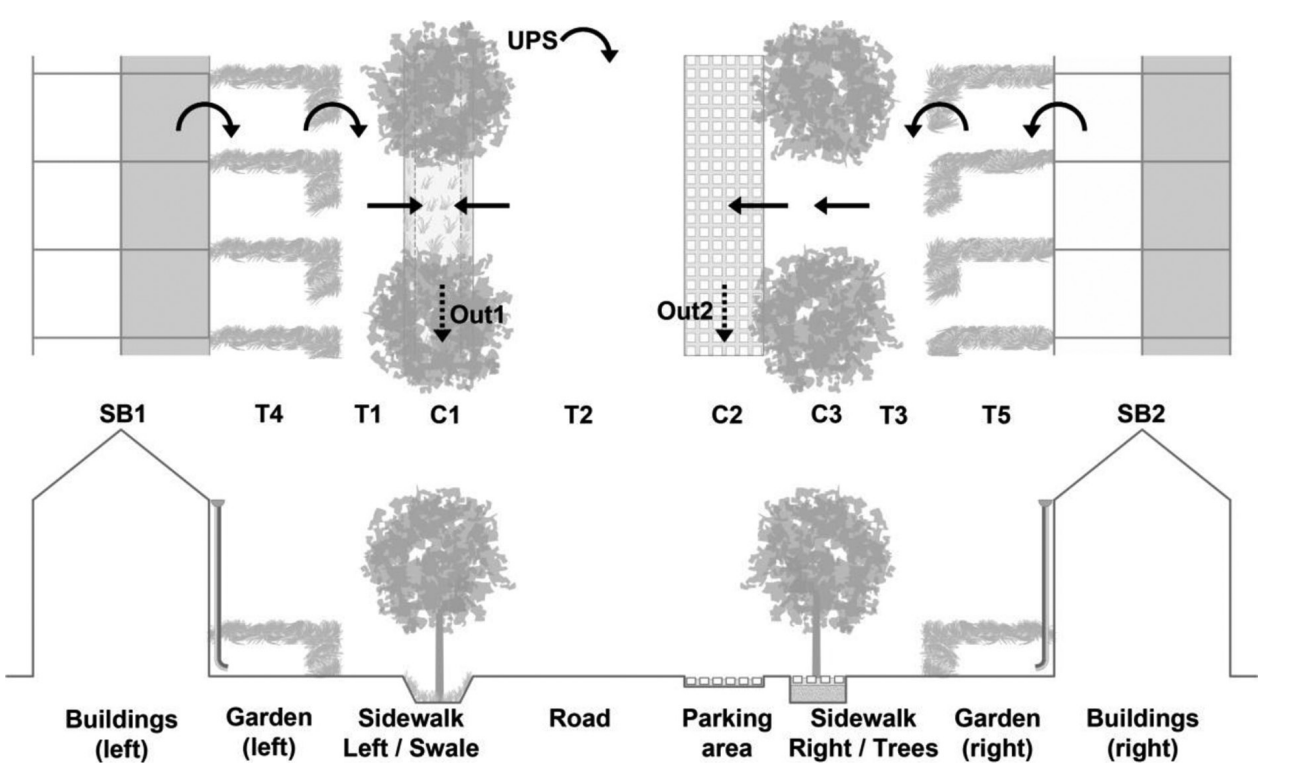

Figure 1: Design of the study site (surfaces and networks).

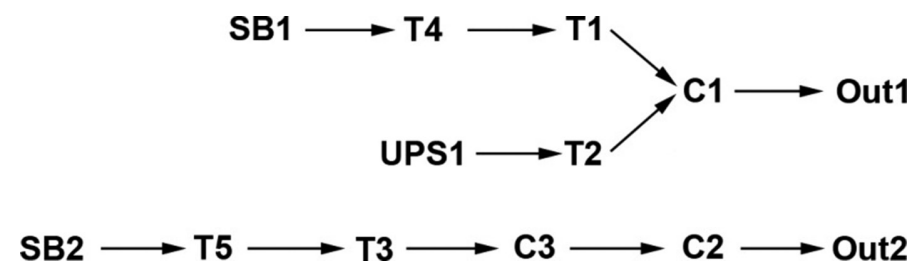

Figure 2: Conceptual networks of the study site.

hydraulic conductivity $\mathrm{K}_{\mathrm{S}}$ was measured on site $\left(\mathrm{K}_{\mathrm{S}}=25 \mathrm{~mm} / \mathrm{h}\right)$. According to a soil regional database the imperviousness rate of the surrounding area is $67 \%$ corresponding to a middle density neighbourhood in Brussels.

The site project is related to the surrounding environment and neighbourhood by the upstream public space (UPS1) identified on site (Fig. 1). Moreover, water falling on the roofs of the surrounding buildings (SB1 and SB2) may run off to the projected street (Fig. 1).

\subsubsection{Project module}

Each tributary surface is identified by its type (i.e. public space, setback area, sloping roof, or flat roof), its dimensions, its covering material chosen in a list of propositions and its vegetation cover (Fig. 3). The tool automatically selects in a database the runoff coefficient corresponding to the covering material that will be used for the calculation of the water balance. Collecting surfaces are identified in the tool by its dimensions and its BMP technique choice (see paragraph 5.3.3). 


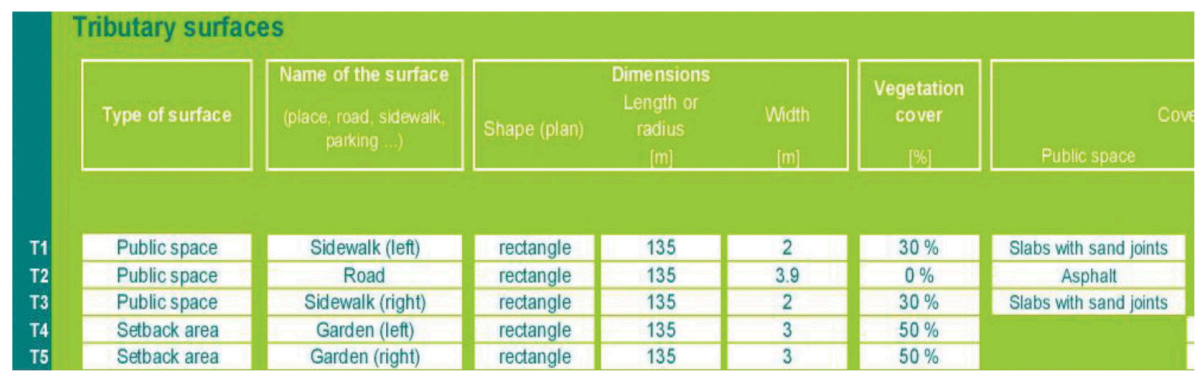

Figure 3: Extract of the characteristics of the tributary surfaces.

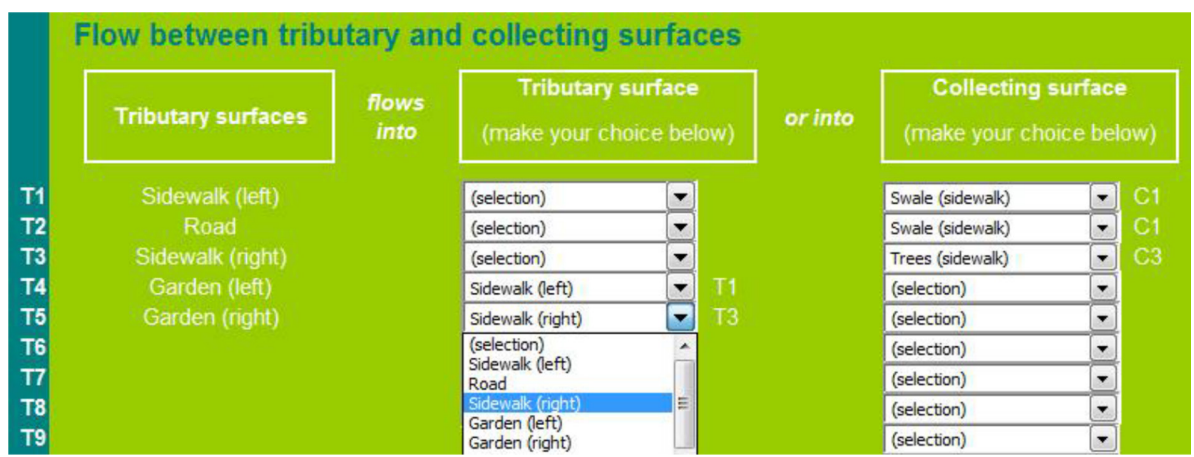

Figure 4: Extract of the entire networks introduced in $Q U A D E A U$.

\subsection{Design scenario}

5.3.1 Design storm and hydrological objectives module

According to the soil imperviousness, the type of project and the local hydrology, both hydrological objectives, i.e. the return period of the design storm and the maximum leakage flow to the outlet, are automatically selected by the tool.

For the case study, the hydrological objectives are a decennial design storm and a 2 1/s.ha leakage flow.

5.3.2 Network module

Corresponding to the conceptual networks shown in Fig. 2, the many connections between surfaces of the project are introduced as summarized in Fig. 4 and as explained in paragraph 2.2.

\subsubsection{BMP module}

QUADEAU orientates the selection of a BMP technique for each collecting surface according to the constraints introduced by the user and explained in Section 3.1. As shown in Table 5, many specific parameters for each previously selected BMP may be adjusted by the user. These parameters are directly introduced by the user or selected within a list. Table 6 summarizes the value of the design parameters for each BMP technique selected for the case study. 

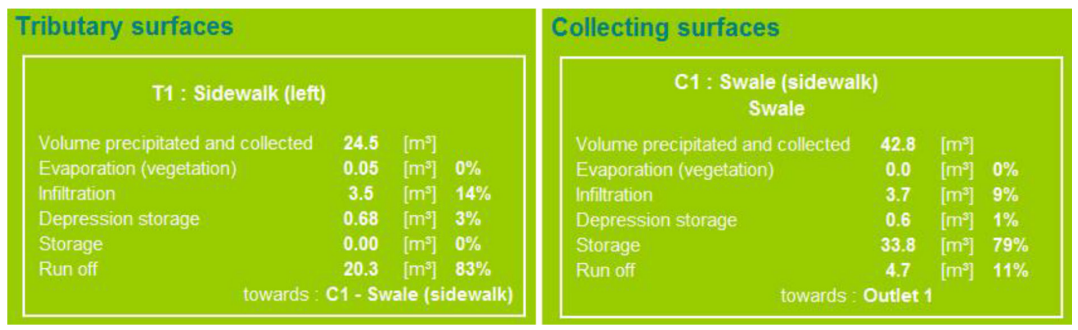

Figure 5: Extract of the water balance surface by surface.

Table 6: Specific design parameters for each selected BMP technique.

\begin{tabular}{|c|c|c|c|c|c|c|c|c|}
\hline & & $\begin{array}{c}\text { Tree } \\
\text { species }\end{array}$ & Swale type & $\begin{array}{l}\text { Pavement } \\
\text { type }\end{array}$ & $\begin{array}{c}\text { Distance } \\
\text { between } \\
\text { trees }\end{array}$ & $\begin{array}{l}\text { Bottom } \\
\text { width }\end{array}$ & $\begin{array}{c}\text { Foliage } \\
\text { cover }\end{array}$ & Depth \\
\hline $\mathrm{C} 1$ & Swale & & Infiltration & Grass & & $0.3 \mathrm{~m}$ & $30 \%$ & $0.5 \mathrm{~m}$ \\
\hline $\mathrm{C} 2$ & $\begin{array}{l}\text { Permeable } \\
\text { pavement }\end{array}$ & & & $\begin{array}{l}\text { Sand joints } \\
\text { cobblestone }\end{array}$ & & & $30 \%$ & \\
\hline $\mathrm{C} 3$ & $\begin{array}{l}\text { Stormwater } \\
\text { trees }\end{array}$ & $\begin{array}{l}\text { Cherry } \\
\text { Prunus }\end{array}$ & & Dolomite & $20 \mathrm{~m}$ & & & \\
\hline
\end{tabular}

\subsection{Outputs}

\subsubsection{Outcomes module}

The water balance for each surface is calculated during the rainfall. Figure 5 below shows an extract of the outcomes for a tributary surface (T1) and for a collecting surface (C1).

\subsubsection{Hydrological efficiency module}

At the end of the evaluation process, $Q U A D E A U$ summarizes the major inputs data encoded within the tool: characteristics of the surfaces, connections of the site to the neighbourhood, design of the networks.

As illustrated in Fig. 6, the hydrological efficiency is calculated and printed for each network of the project.

Analysis of each network is produced by giving the total volume precipitated on each surface composing the network, by giving the complexity of the network (i.e. the number of nodes composing the network) and by giving the most supplied surface of the network. This information may inspire the user for possible optimization.

A water balance analysis of each network is calculated during the rainfall: the tool gives the user the amount of water, all over the surfaces composing the network, intercepted by the vegetation, infiltrated through the soil, stored into BMP, and discharged to the outlet. The amount of water that is greater than or equal to the maximum storage capacity of the network or the maximum authorized flow are highlighted. According to these results, the tool comments the analysis of the networks by telling the user if the hydrological objectives are reached or not. For instance, for the first network 


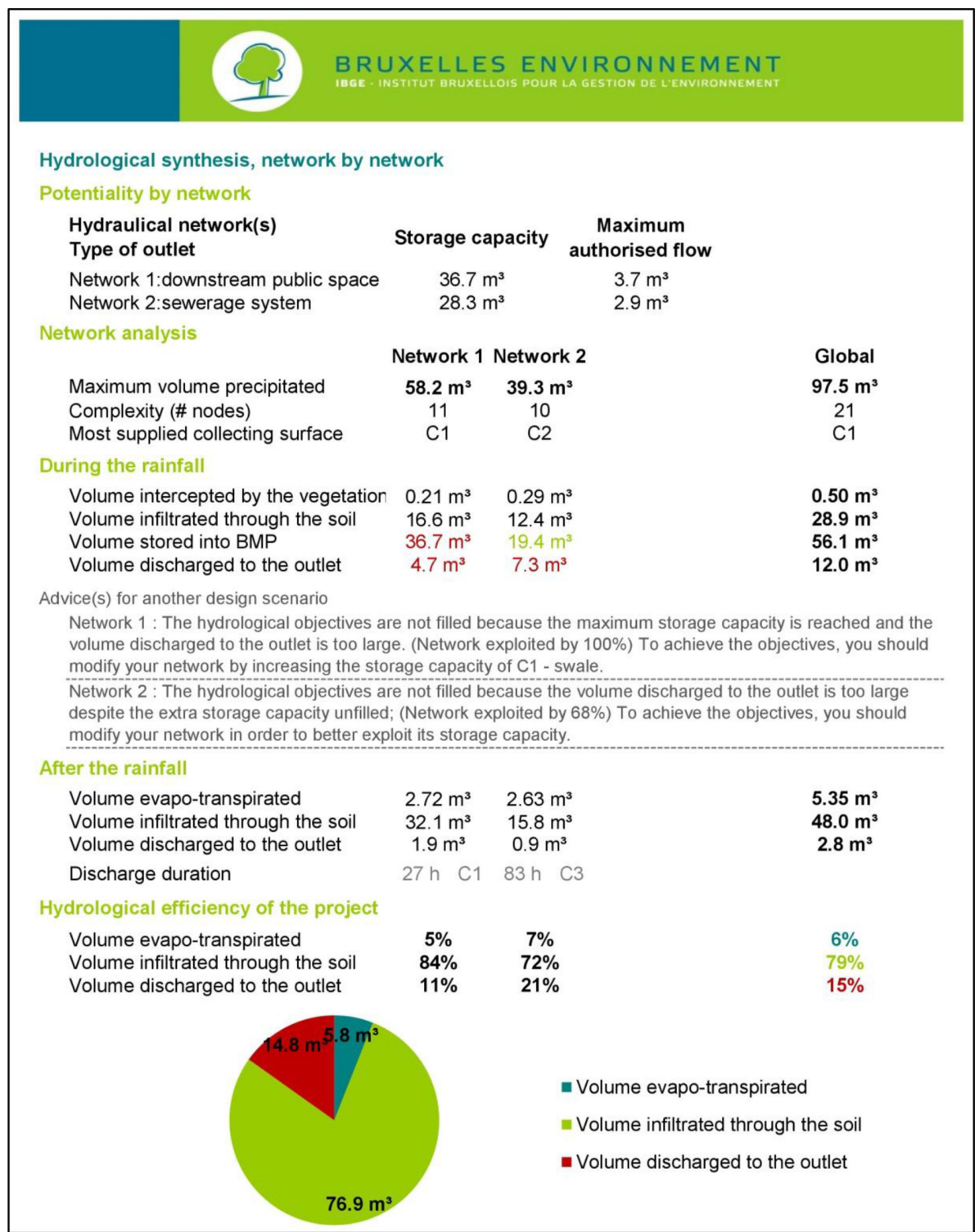

Figure 6: Hydrological efficiency synthesis of the project.

of the illustrative case study, the user may read from the tool: 'The hydrological objectives are not filled because the maximum storage capacity is reached and the volume discharged to the outlet is too large (Network exploited by 100\%). To achieve the objectives, you should modify your network by increasing the storage capacity of $\mathrm{C} 1$ - swale.'

Then the tool describes how and how long the water stored in the many BMP techniques scattered over the networks is discharged to the outlet by evaporation, infiltration, and run off.

Finally, the global hydrological efficiency of the project is graphically produced giving the percentage of water evaporated, infiltrated, and discharged. The hydrological efficiency of the illustrative 
case study is $85 \%$ meaning that the BMPs introduced on the site manage $85 \%$ of water precipitated on the site that was earlier (before renovation) discharged to the outlet.

\section{DISCUSSION}

QUADEAU is a stormwater management tool developed to highlight the potential of a sustainable approach of stormwater management in urban area. The Brussels capital Region hopes to decrease the impact of urbanization on the water cycle by promoting the integration of such approach. QUADEAU is a public domain design support model for analyzing neighbourhood-scale sustainable stormwater drainage system. This model can evaluate alternatives for sustainable stormwater management techniques in urban areas called Best Management Practices. It is a tool designed to provide decision support to urban designer and architects involved in urban projects by evaluating options of integrated stormwater management techniques. QUADEAU can evaluate the effectiveness of diverse BMP applications for urban stormwater management in public space scale. QUADEAU offers in an original way the opportunity to select and evaluate a large amount of specific parameters of BMPs and let the choice between mandatory or voluntary hydrological objectives.

This paper describes globally the $Q U A D E A U$ tool, explains the way the BMPs are selected and designed in the tool and presents the hydrological efficiency evaluation calculation process of a public space project designed with BMPs. BMPs are selected in the tool according to local site constraints, project design, and environmental amenities. QUADEAU calculates, for a public space project, the part of stormwater that is intercepted by the vegetation, that infiltrates through the soil, that accumulates into BMP and that flows into the outlet for a given design storm. The hydrological efficiency is the metric used in the tool to compare the relevance of BMP in stormwater management to conventional drainage system. Based on a water balance approach, the runoff losses are calculated each 5 min of a 4-h design storm statistically constructed. A case study, based on abstract data from a typical Brussels street, was organized to demonstrate how to set up the tool. QUADEAU also integrates the possibility to connect the projected public space with surrounding areas such as private parcels or other public spaces. By this way, the tool operates at the neighbourhood scale.

$Q U A D E A U$ is an oriented-project tool asking the user to introduce geometrical shapes, dimensions, vegetation cover, and covering materials data of each projected surfaces and expected BMPs. The networks are simply elaborate by connecting projected surfaces between each other giving the receiving surface for each surface of the project. All information needed to set up the tool are directly introduced or selected in lists by the user. This simplification of modelling of some complex issues such as urban drainage makes the tool easy-to-use and intuitive without engineering or specific hydrological knowledge.

Although $Q U A D E A U$ realizes a complete water balance for any project of public space, one particular emphasis for the future work will be to define how water quality can be integrated in the BMP modelling and design process. An update to the tool will include the cost of the BMP including the material cost and the cost of labour. Another future development of the tool should include other environmental BMP benefits including carbon sequestration, reduced energy use, and maintenance savings.

\section{REFERENCES}

[1] Vanhuysse, S., Depireux, J., Wolff, E. \& ULB-IGEAT, Etude de l'évolution de l'imperméabilisation du sol en Région de Bruxelles-Capitale, Etude réalisée à la demande du Ministère de la Région de Bruxelles-Capitale, Administration de l'Equipement et des Déplacements/ Direction de l'Eau, 60 pp., 2006. 
[2] Roesner, L., Bledsoe, B. \& Brashear, R., Are best-management-practice criteria really environmentally friendly? ASCE Journal of Water Resources Planning and Management, 27(3), pp. 150-154, 2001. doi: http://dx.doi.org/10.1061/(asce)0733-9496(2001)127:3(150)

[3] CIRIA C687, The SUDS Manual, CIRIA: London, 2007.

[4] Ministère du Développement durable, de l'Environnement, et des Parcs, Ministère des Affaires municipales, des Régions et de l'Occupation du territoire, MDDEP, MAMROT, Guide de gestion des eaux pluviales - Stratégies d'aménagement, principes de conception et pratiques de gestion optimales pour les réseaux de drainage en milieu urbain, 2012.

[5] Elliott, A.H. \& Trowsdale, S.A., A review of models for low impact urban stormwater drainage. Environmental Modelling \& Software, 22, pp. 394-405, 2007. doi: http://dx.doi.org/10.1016/j. envsoft.2005.12.005

[6] United States Environmental Protection Agency (USEPA), National Stormwater Calculator User's Guide - Version 1.1, National Risk Management Research Laboratory, U.S. Environmental Protection Agency: Cincinnati, Ohio, available at http://www2.epa.gov/water-research/ national-stormwater-calculator, 2014.

[7] Water Environment Research Foundation (WERF), WERF BMP Select Model - Version 2.0, Alexandria, Virginia, available at http://www.werf.org, 2013.

[8] Bruxelles Environnement (IBGE), Outil de gestion de l'eau de pluie à l'échelle du quartier, available at http://www.environnement.brussels/thematiques/ville-durable/les-quartiers-durables/les-outils/outil-de-gestion-de-leau-de-pluie?view_pro=1

[9] Romnée, A., De Bondt, K. \& Mahaut, V., Sustainable stormwater management tool at the neighbourhood scale. In Urban Water II, WIT Press: Southampton, Boston, 2014.

[10] De Bondt, K. \& Claeys, P., Urban hydrological landscapes in Brussels (Belgium): what can geosciences bring to stormwater management in cities. Landscape and Urban Planning, to be accepted, 2014.

[11] Rivard, G., Gestion des eaux pluviales en milieu urbain: concepts et applications, Alias communication design: Sainte-Dorothée, Québec, 1998.

[12] Azzout, Y., Cres, F.N., Barraud, S. \& Alfaki, E., Techniques alternatives en assainissement pluvial: choix, conception, réalisation et entretien, ed. Lavoisier, Paris, p. 372, 1994.

[13] Musy, A. \& Higy, C., Hydrologie: Tome 1, Une sciences de la nature, Vol. 21, PPUR presses polytechniques, 2004.

[14] Leeflang, M.J. \& Monster, N.J., The design of infiltration and percolation facilities: literature review, Technische Universiteit Delft, 110 pp., 1995. 